\title{
Editorial
}

\section{Disease markers of the nervous system}

The nervous system is important in controlling cognition and behaviors as well as bodily functions via the peripheral and autonomic pathways. Dysfunction in the nervous system results in diseases that are an increasing burden to modern medicine. Advances in the diagnosis, control and treatment of these diseases will require a comprehensive knowledge of the biochemical changes associated with specific brain functions.

Brain functions are currently identified, and sometimes measured, by clinical structured interviews, coupled with imaging or neurophysiological procedures, such as CT, MR and PET scanning and EEG, MEG and evoked potentials. Far fewer molecular based diagnostic methods, such as disease specific biomarkers, are available at this point to monitor biochemical changes for central nervous diseases. Fortunately, new technologies place medical research on the threshold of discovering a great deal about disease biochemistry, and future advances should be rapid.

To assess current activities in this important field, we invited scientists whose work has been exemplary to write original contributions for a special issue of the journal to be entitled "Disease Markers of the Nervous System." Nine groups have contributed papers that have all been peer-reviewed and accepted for publication. Two have been published in Disease Markers Vol. 21(2) 2005 and the seven remaining submissions are in this volume. "Disease Markers of the Nervous System" is not intended to be comprehensive, but to present - in one publication - a number of relevant articles in this field.

Hühmer and colleagues first set the scene of some of the important issues of cerebrospinal fluid protein analysis summarizing physiological aspects, current progress and future challenges. Three additional papers extend the concept of molecular profiling of cere- brospinal fluid proteins to other general methodological approaches for the analysis of endogenous peptides, lipids and small molecular metabolites. Schrader and Selle present their process chain for peptidomic biomarker discovery. Fonteh and colleagues next describe how both lipidomic and proteomic methods are mutually relevant for the discovery of disease pathways in the brain. And Salomon and colleagues illustrate the need to take into account ultradian variability, focused on their study of depression.

Progressing to individual molecules, Harrington and colleagues define the complex changes that occur both qualitatively and quantitatively in prostaglandin D synthase across a variety of brain pathologies, and Yao et al. present evidence for altered glutathione reductase in the brains of schizophrenics.

Three papers discuss neurodegenerative disease research efforts to find biomarkers. Xiang and colleagues reveal evidence for microglial activation in dementia. In the earlier issue (Disease Markers Vol. 21(2), 2005, pp. 81-92), Davidsson and Sjogren review the use of proteomics and Finehout and colleagues (Disease Markers Vol. 21(2), 2005, pp. 93-101) apply this approach in identifying complement changes in neurodegenerative disease.

We think these articles provide a taste of the field and also highlight how much comprehensive work is needed towards the ultimate goal of understanding diseases of the nervous system on a molecular level. We believe the new technologies of the varied forms of array technologies, chromatography, mass spectrometry and analysis methods, when coupled with well-defined clinical experiments, have the opportunities to make real progress. Only after much more of this work will we achieve the goal of developing informative biomark- 
ers that help in the early diagnosis and successful management of diseases of the nervous system.

We hope this special issue of Disease Markers is useful to researchers and clinicians by highlighting the application of mass spectrometry and bioinformatics to research of the nervous system. We thank the editorial office of Disease Markers for their help and all contributors to this special issue in realizing this project.

Yours sincerely,

Michael G. Harrington, MB, ChB, FRCP

Alfred N. Fonteh, PhD

Molecular Neurology Program

Huntington Medical Research Institutes

99 N. El Molino Ave

Pasadena, CA 91101, USA

Tel.: + 1626795 4343;

E-mail: \{mghworks,afonteh\}@hmri.org

Roger G. Biringer, $\mathrm{PhD}$

Andreas F.R. Hühmer, $\mathrm{PhD}$

Thermo Electron

355 River Oaks Parkway

San Jose, CA 95134, USA

Tel.: +1 408965 6294;

E-mail: \{roger.biringer,andreas.huhmer\}@thermo.com 


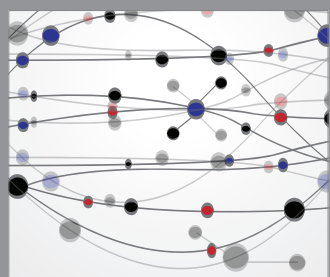

The Scientific World Journal
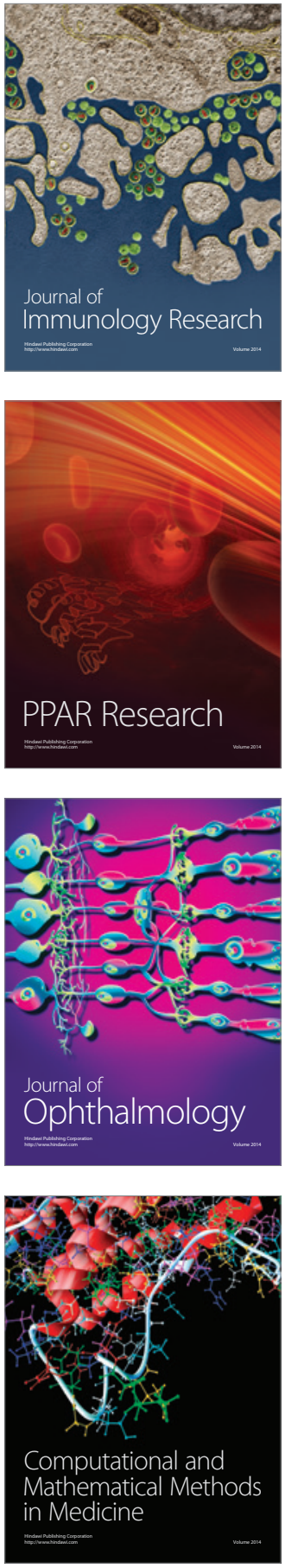

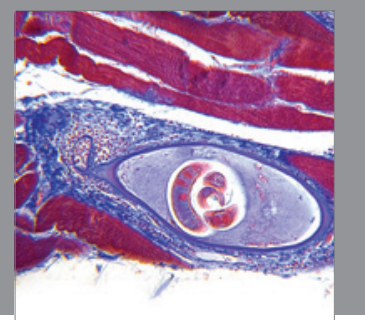

Gastroenterology

Research and Practice
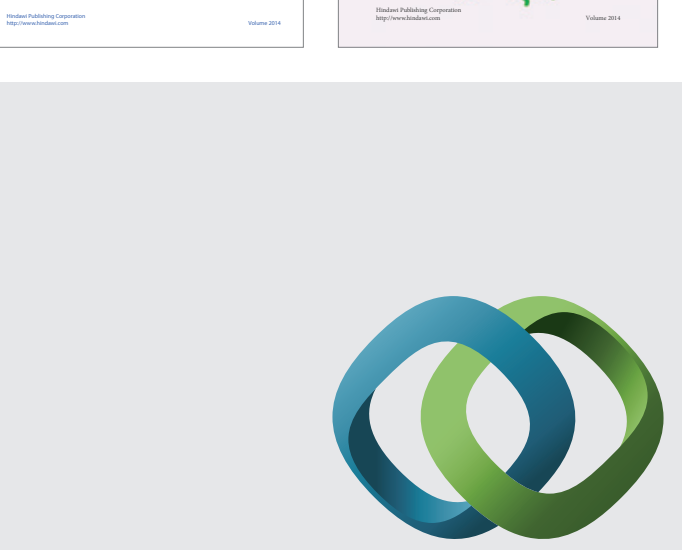

\section{Hindawi}

Submit your manuscripts at

http://www.hindawi.com
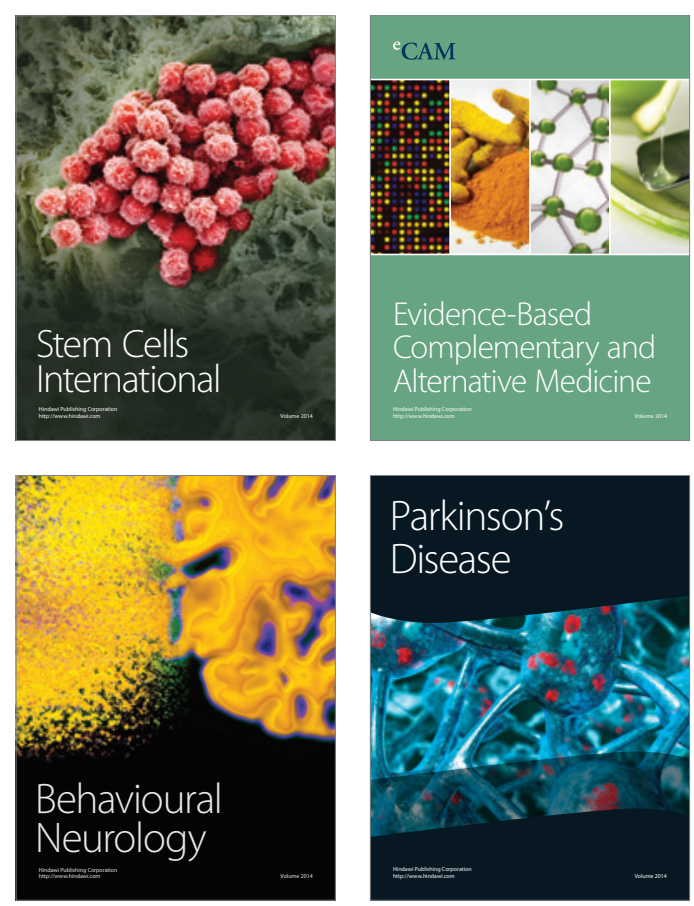

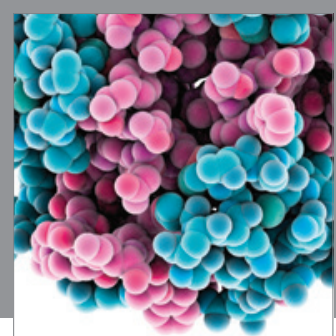

Journal of
Diabetes Research

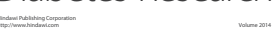

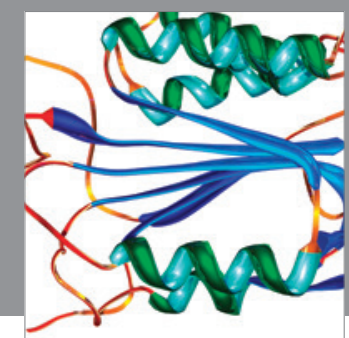

Disease Markers
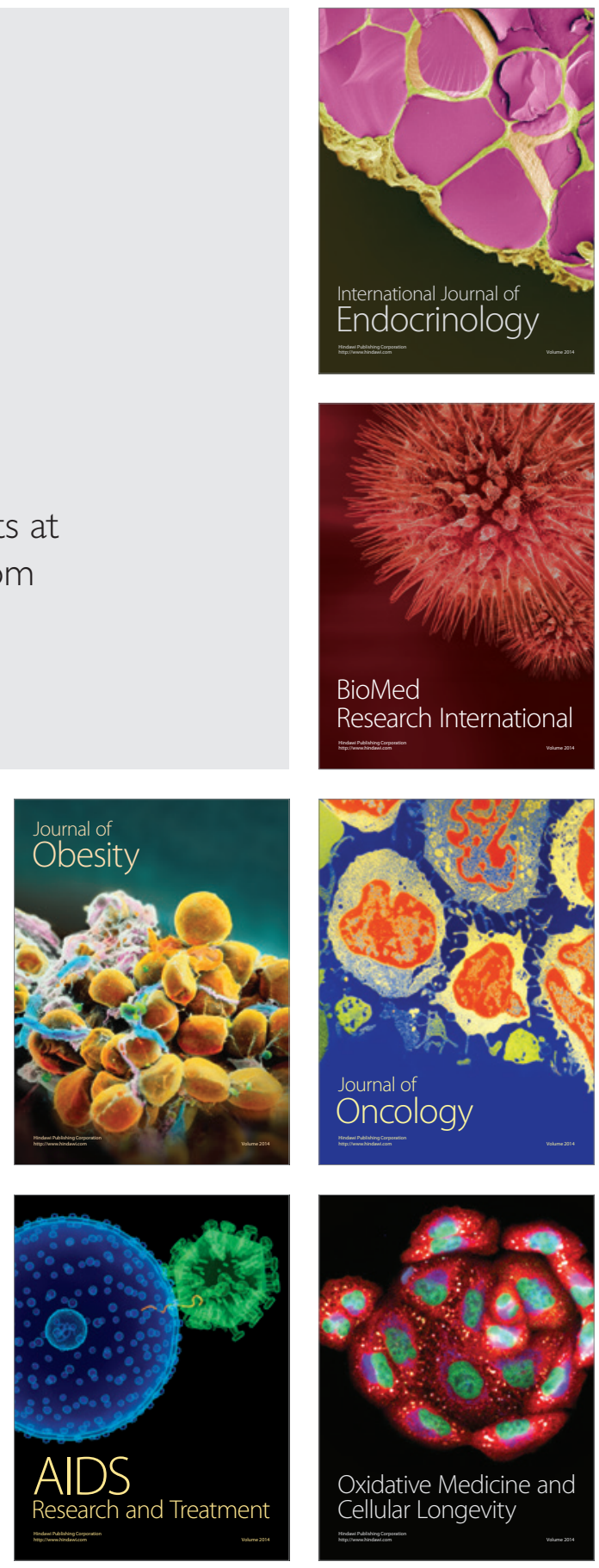